\title{
LA INMANENCIA DEL ENEMIGO
}

\section{Eduardo Viveiros de Castro}

\author{
Pois que trago a mim comigo \\ tamanbo imigo de $\mathrm{mim}^{7}$ \\ Sá de Miranda
}

$\mathrm{E}_{\mathrm{n}}$ este artículo se discuten las relaciones entre el guerrero y su víctima, tal y como son concebidas por los Araweté, un pueblo de lengua Tupi-Guaraní de la Amazonía oriental. Los materiales que ofrecemos a consideración al lector ya fueron presentados en un texto de mayor envergadura; aquí se encuentran de manera resumida y retomados desde una perspectiva comparativa

The relationship between a warrior and his victim are discussed as conceived by the Araweté, a Tupí-Guarani people of the eastern Amazon. The data presented here is part of a larger text which has been summarized and reconsidered from a comparative perspective.

No puedo sino cargar profundo dentro de mi a mi peor enemigo - I’o mismo. 
En este artículo se discuten las relaciones entre el guerrero y su víctima, tal y como son concebidas por los Araweté, un pueblo de lengua TupiGuaraní de la Amazonía oriental ${ }^{2}$. Los materiales que ofrecemos a consideración al lector ya fueron presentados en un texto de mayor envergadura; aquí se encuentran de manera resumida y retomados desde una perspectiva comparativa ${ }^{3}$. Nuestro tema de investigación es la dinámica identitaria involucrada en la determinación del estatus de moropi"nã ("matador") araweté. Nuestra cuestión tiene menos que ver con las funciones -políticas, ideológicas, y otras- asociadas a este estatus, que con su constitución misma, la cual es realizada a través de ciertos procesos rituales. Confiamos en que este examen pueda contribuir a una mejor comprensión de un régimen simbólico de amplia difusión en la Amazonía indígena, una economía de la alteridad en la cual el concepto de 'enemigo' señala el valor cardinal.

\section{ELEMENTOS DE COSMOLOGÍA}

El universo de los araweté tiene su origen y fundamento en la diferenciación entre la humanidad (bide) y la divinidad (Mai). Esta diferencia fue creada por la separación entre el cielo y la tierra, al comienzo de los tiempos. Por causa de una disputa que opuso a los hombres contra los futuros dioses, estos últimos partieron, llevando el firmamento y llevándose consigo la ciencia de la juventud eterna y de la abundancia sin tener que trabajar. Desde entonces, los humanos se definen como "los abandonados" (beña mi re), los que fueron dejados atrás por los Maï. Todo lo que existe sobre la tierra comparte una condición general de minoridad ontológica

\footnotetext{
2 Este trabajo fue presentado originalmente en el seminario del grupo de investigacion "Anthropologie Comparée du Champ Religieux" dirigido por Marcel Detienne, en la Fcole Pratique des Hautes F.tudes, en mayo de 1992. Resume tres conferencias hechas en la Maison Suger, en el mismo mes ! año, bajo el patrocinio del provecto "Nouvelles approches de la tradition: représentation et communication des connaissances culturelles" del laboratorio de Anthropologie Sociale (Collège de France) y dellaboratorio de Fthnologie et de Sociologie Comparative (Nanterre). Ayrade\%co a Marcel Detienne, Carto Severi, Michael Houseman y Pascal Bover por las invitaciones a estos debates. Viveiros de Castro 1992a
} 
frente a las personas y las cosas que pasaron al nivel celestial. En particular, los vivientes terrestres están sometidos al tiempo, es decir, son mortales.

Sin embargo, entre todos los seres perecederos de nuestro nivel cósmico, los humanos ocupan un lugar aparte: son "los que se irán" (uha me'e rin), los únicos que se juntarán póstumamente a los Maï. Cuando acontece la muerte, una parte de la persona, el in o 'alma', sube a los cielos, donde es recibida por los Maï-bete, los 'dioses por excelencia', la raza divina más directamente interesada en la humanidad ${ }^{4}$. Los Maï-hete se asemejan a los Araweté, salvo que son más bellos, más altos y más fuertes que cualquier humano, como es el caso para todo lo celestial. La ornamentación corporal de los dioses es una hipérbole de la ornamentación típica del grupo en ocasiones ceremoniales: piel y cabellos untados de achiote rojo-vivo, salpicados con plumas blancas de pecho de gavilán-real, coronas de diademas hechas de plumas de papagayos rojos; aretes floriformes compuestos de plumas amarillas de tucán y azul turquesa de cotinga. Pero los Maï ostentan, además, diseños geométricos espléndidos sobre sus cuerpos, grecas, rombos y riscos hechos con el jugo negro-azulado del huito (Genipa americana). Este estilo es característico de varios enemigos de los Araweté, en particular de los temidos Kayapó. Los Araweté se untan el rostro y el cuerpo con el jugo de este fruto, el cual es asociado al jaguar, cuando van a la guerra o a la caza, pero nunca lo usan para pintarse el cuerpo. Los Maï, en suma, tienen una apariencia que mezcla rasgos Araweté y de sus enemigos.

Por esta razón, los Araweté afirman que los Maï, aun siendo "como nosotros", son al mismo tiempo "como enemigos". No solamente porque se pintan como enemigos, sino sobretodo, porque son feroces y peligrosos. Los Maì son antropófagos. Matan y comen a los muertos apenas éstos llegan a los cielos. Enseguida, los rehacen, zambullendo los huesos de sus víctimas en una batea de piedra llena de agua mágica, que hierve (-pipo,

Existen decenas de razas o especies divinas, con nombres y atributos propios. Fl sufijo modificador - lete indica la prototipia y autenticidad del referente del concepto modificado, sirviendo también como marcador de énfasis y de ipseidad. 
hervir o fermentar) sin fuego. Entonces, los muertos resucitan, volviéndose "como los Mai", es decir, eternamente jóvenes y bellos. Los muertos hechos divinos se casan con los dioses, regresando a la tierra junto con ellos para compartir los alimentos ofrecidos por los humanos al pueblo celestial, en la ocasión de los rituales. Los chamanes (peye), en sus viajes al cielo, tratan con los dioses y con los muertos, trayéndolos a la tierra a menudo para que participen de estos banquetes festivos, o simplemente para conversar con los vivos. El chamanismo araweté es esencialmente un dispositivo de intercambio entre los vivos y los Maï. Los humanos dan de comer a los dioses, tanto en el sentido alimentario como en el sexual ${ }^{5}$, recibiendo de ellos a cambio cantos (la «música de los dioses» cantada por los chamanes) y otros bienes espirituales: la vida póstuma en los cielos, por supuesto, pero también la persistencia del mundo, puesto que el consumo caníbal y sexual de los muertos por los Maï impide que los Maï hagan caer el firmamento, aplastando a la tierra.

Los dioses araweté son ambiguos de más de una manera. A diferencia de lo que sucede con la mayoría de las cosmologías tupi-guaraní, la de los Araweté no concibe a los Maï como héroes culturales, padres creadores, o señores de la humanidad ${ }^{6}$. Los dioses araweté están al mismo tiempo más allá y por debajo de la cultura o civilización. Si bien disponen de una ciencia chamánica absoluta, capaz de resucitar a los muertos o hacer que los instrumentos trabajen solos, no dejan, sin embargo, de ser definidos como primitivos (uka-hete me'e, "meramente existentes", así como se dice de los animales), gente sin fuego y sin plantas cultivadas. Estas conquistas de la civilización no se deben a los Maï. Contrariamente, fue un humano quien las enseñó, tanto a los humanos como a los Maï, en los tiempos ancestrales. Así, a pesar de que actualmente los Maï utilizan una tecnología culinaria similar a la de los humanos, un curioso epíteto continúa a marcar a los dioses como

Así como es el caso de tantas otras lenguas, el rocabulario araweté de alimentación se aplica también al comercio carnal.

Maïes un cognato de Maira, el nombre muy difundides entre los Tupi para los demiurgos o héroes culturales que se apartaron de los hombres al comien\%o de los tiempos. 
salvajes: me'e wi a-re, "comedores de carne cruda", expresión que describe de manera ejemplar a los jaguares ${ }^{7}$.

Es preciso comprender lo que los Araweté quieren decir cuando afirman que los Maï son "como enemigos" (awin berin). Los dioses son como enemigos porque tratan a los muertos araweté como si éstos fuesen enemigos: los matan y los devoran. Pero lo hacen porque los muertos se comportan como enemigos frente a los dioses: un muerto reciente es un ser feo, sucio y mezquino, lleno de rencor por haber muerto. Al llegar al cielo, las almas masculinas son acogidas por los Maï con exigencias insistentes de regalos preciosos; las almas femeninas, con exigencias de favores sexuales. Como los muertos siempre son muy avaros, negándose a establecer relaciones con los Maï, se hacen matar. Los dioses, entonces, son "como enemigos"; la verdad, sin embargo, es que los muertos son los verdaderos enemigos puesto que los señores de la perspectiva celestial son los dioses. Finalmente, esto propicia que los Maï sean "como nosotros" (bïde berin) ellos son los detentores legítimos de la posición de sujeto en su mundo.

La palabra bïde, que traduzco como "humanidad", significa también "nosotros", "la gente", y "los Araweté". Es de notar que no se trata de un etnónimo, equivalente a 'Araweté' (palabra inventada por los blancos) o de una 'autodesignación' substantiva y distintiva. B̈̈de es sintácticamente y semánticamente equivalente a ñane, el pronombre de la primera persona del plural inclusivo (por oposición a ure, primera del plural exclusivo). Bïde es una marca de la posición enunciativa, se trata efectivamente de un pronombre que marca la posición de sujeto, no de un nombre propio. Como otras sociedades amazónicas, los Araweté no objetivizan el colectivo al que pertenecen por medio de sustantiros de tipo etnónimico, reservándolos para los demás, es decir, precisamente, para los enemigos (awin $)^{8}$.

La palabra wi corresponde al castellano "sang re" y, aplicada especificamente a la carne, a lo'crudo". Recuerdo que uno de los epítetos de Dionisio era exactamente este: omestes o omadios, "comedor de carne cruda" (Detienne 1977:150).

Viveiros de Castro 2002 a 
La ambigüedad categorial de los dioses refleja su estatuto sociológico: futuros cónyugues de los muertos, los Maï son afines de los vivos. Los Maï-bete, en particular, reciben el epíteto de ure tiwà obo, "nuestros gigantescos-temibles afines potenciales". Tiwã, afín potencial o primo cruzado, es un término que se aplica a todo no-pariente, conllevando connotaciones agresivas y/o lascivas, $y$ no debe de ser normalmente empleado como forma de tratamiento para un conciudadano. Un tiwa es casi un awin, un enemigo, pero un enemigo concebido bajo el modo de la alianza posible. Los Araweté designan por tiwã a todos los no-Araweté con quienes establecen relaciones diferentes de aquellas, globales e impersonales, que están en vigor entre ellos y los enemigos colectivos.

Feroces pero espléndidos, peligrosos pero deseados por los humanos, homófagos pero provistos de una supercultura chamánica, enemigos pero aliados, los Maï están marcados por una ambivalencia fundamental. Son al mismo tiempo el 'ideal de Ego' araweté y el arquetipo del Otro. Los Araweté se ven a sí mismos con los ojos de los dioses, al mismo tiempo en que ven a los dioses desde el punto de vista humano, terrestre y mortal.

\section{EL MATADOR Y SU VÍCTIMA}

Aunque los muertos araweté son enemigos - ya sea para los humanos, puesto que la muerte genera un espectro terrestre que asombra a los vivos hasta la desaparición de las partes blandas del cadáver, ya sea para los dioses, puesto que las almas celestiales se comportan de manera no civil al adentrarse en el paraiso -, $y$ aunque los Maï son a su modo igualmente enemigos, no hay, sin embargo, lugar en el cielo para los enemigos humanos de los Araweté. Las almas de los enemigos muertos no encuentran acogida, ni siquiera caníbal, entre los Maï, quienes las mandan de regreso a la tierra, en donde perecen definitivamente.

Pero el caso del enemigo muerto por los Araweté es muy diferente. El alma de un moropi'nà (matador) araweté ý la del enemigo que él mató no 
solamente suben a los cielos, sino que ahí disfrutan de una situación especial. Ellas se funden en una entidad dual que, como veremos, es tratada por los Maï con la atención y cautela debidas a quien está a su altura.

Después de haber matado, o simplemente herido, a un enemigo en una escaramuza, un hombre "muere" (umanun). Apenas regresa a su aldea, cae en una especie de estupor, permaneciendo inmóvil y semiconsciente por varios días, durante los cuales no come nada. Su cuerpo está lleno de la sangre del enemigo, a la cual él vomita incesantemente. Esta muerte no es simplemente un alejamiento del alma (que sobrevicne varias veces en la vida.de una persona), sino un verdadero volverse cadiver. El matador escucha el ruido de las alas de los buitres que se reúnen en torno de 'su' cuerpo - es decir, del cuerpo de su enemigo dejado en el bosque -; siente "como se está pudriendo", sus huesos se ablandan y huele mal.

Cuando el enemigo muere ( $y$ no fue solamente herido), el estado de muerte del matador dura cerca de cinco dias. Debe beber una infusión amarga de cáscara de iwira’ (Aspidosperma sp.), la misma que toman las mujeres durante las reglas y los padres durante la covada. No puede tocar ninguna parte del cuerpo de su víctima, bajo pena de ver su propio vientre hincharse y explotar en una especie de parto mortal.

El matador también esta sometido a una prohibición más larga. Durante varias semanas después de su hazaña, no puede tener comercio con su esposa. El espíritu del enemigo estando "sobre él", sería el primero en penetrar sexualmente a su mujer; el matador, "viniendo detrás del enemigo", seria contaminado por el esperma de la víctima, lo que acarrearía su muerte inmediata.

El periodo de abstinencia termina cuando el espíritu de la víctima decide irse a los confines de la tierra a "buscar cantos". Al regresar, transmite estos cantos al matador durante un sueño, así como la serie de nombres personales que son conferidos a los recién nacidos. De noche, el espíritu del enemigo despierta bruscamente al matador, exhortándolo: "vamos, tiwã, 
levántate y dancemos!". Se dice que el enemigo está enfurecido contra el matador, pero al mismo tiempo, se encuentra indisolublemente ligado a él. Al pasar el tiempo, esta rabia se transforma en amistad; la víctima y su matador se vuelven "como apibi-pibä". Apibi-pibã es el nombre de la relación más valorizada en la sociedad araweté. Se trata de una forma de amistad ceremonial en la cual dos matrimonios comparten sexualmente a los cónyugues de sexo opuesto, pasando largos períodos juntos en el bosque en expediciones de cacería, y forman parejas obligatorias para las danzas colectivas que ocurren durante las fiestas de bebida.

Puede verse aquí una nítida progresión en las relaciones entre la víctima y su matador. Van de la alteridad mortífera a la identidad fusional: alguien que era un puro enemigo, un awin se transforma, primeramente, en un tiwà, un afín potencial; enseguida, se convierte en un amigo ritual, una especie de doble social y afectivo del Yo que es en verdad un anti-afin, puesto que se trata de alguno con quien se comparten esposas en vez de intercambiar hermanas. Finalmente, al morir el matador, la víctima se consubstancializa a su persona: permanece para siempre "con" (-rehewe) o "en" (-re) el matador, volviéndose como un apéndice suyo, distinguiéndolo del común de los mortales en el mundo celestial.

Nótese que, al principio, las relaciones sexuales del matador con su esposa eran peligrosas porque el esperma del enemigo podía contaminarlo; al contrario, la transformación subsecuentemente de la víctima en el apibipibã del matador sugiere la mezcla de simientes, ya que comparten las mismas mujeres. Es más, es de notar que este acceso común a los cónyugues respectivos, al distinguir a los amigos rituales de los cuñados, parece aproximarlos a la relación entre hermanos del mismo sexo, los cuales tienen oficiosamente tal prerrogativa. Sin embargo, aunque las relaciones de apibipibà pueden ser establecidas entre personas relacionadas por una variedad de lazos de parentesco previos, excluyen precisamente a dos tipos de lazo: aquellos entre cuñados y aquellos entre hermanos. Dos hermanos reales no pueden jamás entrar en relaciones de amistad ritual - la inversión de la afinidad (el amigo como 'anti-afín'), no reconduce, por lo tanto, a la mera 
consanguineidad, sino que crea una tercera posición. De un modo general, los apibi-pibá son reclutados en la periferia de la parentela, es decir, en la esfera donde se encuentran los tiwàa, no parientes o parientes lejanos, que pueden ser alternativamente afinizados o transformados en amigos rituales.

\section{LA MUERTE VENTRÍLOCUA}

Durante la danza que clausura la reclusión de moropinnà y celebra la muerte del enemigo, se dice que el espíritu de este último se coloca justo detrás del matador, que es el cantante de la ceremonia. El enemigo es su "profesor de canto" (marakāmemo'o-bä), soplándole al oído las palabras de la canción que debe de proferir, las cuales son retomadas por la comunidad masculina de la aldea reunida a su alrededor. Por lo tanto, aunque durante la reclusión el enemigo "venía por delante", lo que volvía peligrosas a las relaciones sexuales, en la danza guerrera el enemigo pasa a ocupar una posición posterior. Si primero, había una especie de competencia de cuerpos entre enemigo y matador (el riesgo de la mezcla seminal), después en la danza se da una colaboración entre los dos, manifestada en una comunión de palabras.

Los enemigos reciben por lo general dos epítetos muy sugestivos: kà un nabi, "salsa de caium" (la cerveza de maíz servida durante la danza conmemorativa), y maraká nin, "futura música". El primero es una clara alusión caníbal. Aunque los Araweté no comen a sus enemigos, puesto que la antropofagia es propia de los dioses, por lo menos los utilizan para darle gusto a la bebida, infundirle 'espíritu'. El segundo indica la función principal de los enemigos: traer nueros cantos. Vistos por su buen lado - su lado muerto -, los enemigos son aquellos que traen nuevas palabras al grupo, o por lo menos que vienen a dar un sens plus pur aux mots de la tribu (un sentido más puro a las palabras de la tribu)". Las canciones cantadas durante las

Puema de Mallarmé "Tombeau de Por". "Tumbin de Pox". 
danzas araweté, especialmente durante las fiestas de caium que se llevan a cabo varias veces al año, son todas canciones de los enemigos cantadas originalmente por un matador.

Las awin marakã ("música de los enemigos", expresión con sentido tanto genitivo como posesivo) son simples: cuatro a ocho versos repetidos decenas de veces, de ritmo binario y línea melódica monótona. Son cantadas en un registro grave por toda la comunidad masculina, en unísono, después de que el matador haya propuesto las palabras. Cada enemigo muerto puede dar varias canciones a su matador. Una vez enunciadas en la danza que conmemora el final de la reclusión de homicidio, los cantos de los enemigos caen en el dominio público, pudiendo ser retomados por cualquier hombre que se encuentre en la función de cantante durante una fiesta de borrachera con caium.

La esencial complejidad de estas canciones reside en su régimen enunciativo, marcado por el punto de vista del enemigo. El sujeto de la enunciación es siempre la víctima, quien puede estar hablando en su propio nombre, pero también puede estar citando las palabras de terceros. El estilo citacional típico de las narraciones araweté llegan a un gran rendimiento en los awin maraká, creando un juego intrincado de identificaciones entre los dos cantantes, la víctima y su matador. Veamos, a título de ejemplo, una canción atribuida a Yakati-ro, un hombre araweté fallecido en 1976, que le fue enseñada por una víctima del pueblo Parakanã:

1. "Estoy muriendo" -

2. así decía el finado Moiwito;

3. asi hablaba mi presa,

4. así hablaba el finado Koiarawi;

5. En su amplio patio

6. "Eh! - dice el Towabo,

“.urí está mi prisionero, atio del gran pájaro". 
El muerto que dice estar muriéndose - el finado Moiwito o Koiarawi - es un hombre araweté que cayó bajo las flechas parakanã poco antes de la expedición de represalia de los Araweté, mientras que el enemigo que habla en esta canción fue muerto por Yakati-ro. De esta forma, en el verso $\mathrm{N}^{\circ} 3$, el enemigo-cantante se sitúa a sí mismo como el matador de Moiwito, y cita lo que dice su víctima: "Estoy muriendo". En la segunda parte del canto, marcado por un cambio de tiempo, el sujeto del enunciado cambia. El verso $\mathrm{N}^{\circ} 5$ se refiere al buitre, evocado en el verso $\mathrm{N}^{\circ} 8$ por el circunloquio de "gran pájaro". El "patio del gran pájaro" es una metáfora macabra para el claro abierto por los buitres en el bosque en torno al cadáver del enemigo muerto - entiéndase, del cadáver del hombre parakanã que es el sujeto de la enunciación de este canto, no de Moiwito. Las palabras de esta segunda parte del canto son atribuidas al Towalso mencionado (por el enemigo) en el verso $\mathrm{N}^{\circ}$ 6. Towialio es el nombre de una antigua tribu enemiga de los Araweté ${ }^{10}$ que funciona como una sinedoque para 'enemigo' en muchas narraciones tradicionales. Pero, en el presente canto, el Towabo no es nadie mas sino el propio Yakati-ro, es decir, el matador araweté que está cantando la canción enseñada por el enemigo. Desde el punto de vista de la víctima parakana, su matador es un towaho, un enemigo; Yakati-ro, el matador-cantante, habla de sí mismo, hablando las palabras de su víctima, las cuales son una citación de lo que él estaría diciendo: el matador 'repite' por lo tanto sus propias palabras. Una especie de serie enunciativa de ecos o un proceso de reverberación: un enemigo muerto cita a su víctima araweté (verso $\mathrm{N}^{\circ}$ 1), y enseguida cita a su propio matador (versos $\mathrm{N}^{\circ} 5-8$ ), todo esto por la boca de este último, quien cita globalmente lo que su víctima está diciendo. Los que acaban por hablar, o ser citados, son todos araweté: el muerto Moiwito, el matador Yakati-ro, pero ambos desde el punto de vista de un tercero, la víctima enemiga. Y uno se queda sin saber delante de esta construcción en abismo: ¿Quién habla en este cantar? ¿Quién es el muerto? ¿Quién el enemigo?

La palabra es una probable contracción de ton'à obo, "enemigo monstruoso (grande)". Ton'à, que no existe en araweté como lexema autónomo, sería tal ve\% un cognato de forma tupi-guarani más comun para "enemigo", torajar o tonrajat (ḉ. tupinambá torajara, enemigo y cuñado). 
Véase otro ejemplo, un tanto más bucólico. Trátase de un canto enseñado a Kañiwidin-no por el espíritu de un hombre del pueblo Asuriní, herido por él al comienzo de los años 70:

1. "El halcón tata se regocija"

2. - dice la cotinga (posada) en el pequeño arco;

3. "Él está alegre en la rama de yocin",

4. - así oyó mi mujer;

5. "La taquarinha se desvía

6. se desvía de nosotros;

7. se desvía de nuestro camino"

9. - así conversaba mi mujer.

Aquí el enemigo que escapó con vida de las flechas de Kañiwidin-no, se regocija por su suerte. Cita lo que dice u oyó su esposa. La primera parte del canto evoca al halcón tata saltando alegre en una rama de árbol yocin; una cotinga posada en el arco del cantor es quien le dice esto a la esposa del enemigo. La segunda parte conmemora la mala puntería del cantor, cuya flecha de bambu ("taquarinha") "11 se desvió del enemigo y de su mujer. Aquí también el enemigo cita a su esposa.

Al transcribir este canto, el antropólogo objetó a sus interlocutores: pero el enemigo asuriní fue flechado cuando estaba solo en el bosque. ¿Quién, es entonces esta mujer que habla? Ellos explicaron: "mi mujer" designa a la esposa del cantante, pero quien estaba diciendo "mi mujer" era el espíritu del enemigo. El canto es enunciado desde su punto de vista: las flechas se desvían de él. Pero el régimen enunciativo hace que el cantante, refiriéndose a la propia esposa como "mi esposa", esté en verdad citando las palabras del enemigo. Yáa hemos visto las precauciones que el matador debería tomar con respecto al sexo justo después del homicidio; su esposa, de hecho, se convierte en una esposa de enemigo.

Epiteto irónico, puesto que la punta de las flechas araveté es una respetable lámina de Giradua superta de hasta $60 \mathrm{~cm}$ de largo, mucho mayor que las flechas asurini. 


\section{EL DESTINO DEL GUERRERO}

La reverberación entre el matador y su víctima se encuentra en el origen de la situación paradójica de la danza guerrera, situación de mayor cohesión social y de máxima 'efervescencia colectiva' en la sociedad araweté, cuando la comunidad masculina se reúne en torno del matador para, identificándose a él, repetir las palabras enunciadas por otros. Este proceso, como se puede imaginar, tiene su precio. La fusión entre el matador y el enemigo presupone un devenir-otro del matador: el espíritu de su víctima jamás lo deja. Apenas mata a su enemigo, las armas del matador deben de ser apartadas de él; el espíritu del muerto, lleno de sentimientos de venganza, le inspira un furor homicida capaz de voltearlo contra los suyos. Un guerrero permanece expuesto a este peligro durante mucho tiempo después de su hazaña. Es frecuentemente presa de accesos de rabia que deben ser apaciguados por sus amigas rituales (las esposas de los apibi-pibaj, ver supra). A veces necesita huir al bosque porque el enemigo "empluma su cabeza" y le trastorna los sentidos. "Cuando llega sobre el matador, el espíritu del enemigo lo transforma en un enemigo para nosotros", me decían los Araweté. El enemigo no puede vengarse del matador, ya que es una parte suya; por lo que intenta vengarse sobre los conciudadanos de su matador. Solamente muchos años después, al parecer, entra en aquiescencia y deja en paz al homicida.

Los moropi"ña araweté son conocidos como personas temperamentales, capaces de pasar a los hechos cuando están irritados. En esto, se distinguen de las personas marin-in me'e, "inofensivas" (todos los no-matadores), que muestran, normalmente, un notable autocontrol. La posición de matador no confiere privilegios ceremoniales, y tiene como única marca visible la falta de flequillo, puesto que el espíritu del enemigo hace caer los cabellos de la frente del homicida. Pero ésta es una condición honrosa; los moropïnã son admirados y ligeramente temidos. Los seis hombres que tenían este estatus en 1991 estaban entre las pocas personas que nunca eran objeto de la maledicencia y el sarcasmo tan apreciados por los Araweté, el cual no perdona ni siquiera a los chamanes de gran reputación. El colapso demo- 
gráfico causado por el contacto en 1976, hizo que los Araweté perdiesen en poco tiempo a ocho matadores, y esto es frecuentemente lamentado. Antiguamente, "todos los hombres eran matadores, sin excepción". Declaración ciertamente exagerada, pero que expresa, también con certeza, un ideal.

La diferencia metafísica de la persona del matador sólo se revela plenamente después de la muerte. Ser devorado póstumamente es el destino de todo individuo, macho o hembra, chamán u hombre común. Ĺn único estatus coloca a su titular al abrigo del canibalismo divino: el de moropïnã. El espíritu de un matador sube a los cielos fundido con el espíritu de su víctima. Ahí, ellos se transforman en un Iraparadi, un tipo de entidad que los Maï temen y respetan. Un Iraparadï, el alma del matador araweté aumentada de su suplemento enemigo, no es devorada por los dioses. Pasa directamente al baño de inmortalidad, transformándose en un ser incorruptible sin sufrir la prueba de la muerte caníbal. Es posible, tal vez, que el matador deje, pura y simplemente, de pasar por la prueba de la muerte. Se cuenta de varios guerreros de la antigüedad que no murieron, habiendo subido a los cielos en carne y hueso. La idea a veces se expresa de modo dogmático: "un matador no muere".

Vimos que, al matar a un enemigo, el matador "muere", y enseguida resucita aquí mismo en la tierra. De este momento en adelante, se puede decir que es inmortal, puesto que no es devorado al llegar al cielo. Él es en sí mismo un caníbal (su vientre está lleno de la sangre del enemigo); y él ya es un enemigo, una fusión compleja de atributos bïde y awin. En suma: él ya es un Maï. El matador es un dios anticipado: encarna a la figura del enemigo siendo al mismo tiempo el Araweté ideal.

El consumo caníbal de los muertos en el cielo es la condición de su transformación en seres inmortales, dotados de un cuerpo glorioso e incorruptible. Pero como el matador es un otro - siendo un enemigo - ya sufrió su apoteosis. En la antigüedad ejemplar, los matadores subían a los cielos en sus cuerpos; hoy en día, el cuerpo enterrado de un matador se pudre, como todos pueden atestar; pero algunas personas me sugirieron que su cadáver 
no produce el espectro terrestre, malvado y repugnante que emite todo cadáver. Me dijeron, alternativamente, que los moropi"nà muertos producen, eso si, un espectro, pero que éste es "inofensivo", al contrario del espectro de las personas comunes - que eran, al contrario de los matadores, inofensivas cuando estaban vivas.

En tanto que transformación final de la condición de matador, el concepto de Iraparadï se manifiesta esencialmente como una perspectiva. Si los dioses caníbales son, al mismo tiempo, el equivalente celeste de los Araweté y una figuración del Enemigo, si ellos nos ven con ojos de enemigo y si nosotros los vemos como enemigos, la perspectiva del Iraparadï muestra a los Araweté viéndose activamente a sí mismos como enemigos. Esta capacidad de verse como otro - punto de vista que es, tal vez, el ángulo ideal de la visión de sí mismo - me parece ser la llave de la antropofagia tupi-guaraní. En fin, si es verdad que "el caníbal es siempre el otro" (Clastres y Lizot 1978:126), entonces ¿qué es un Iraparadi sino el Otro de los Otros, un enemigo de los dioses que, por eso mismo, se vuelve como éstos, un dueño del punto de vista celeste?

El ideal de que, antiguamente, todos los hombres eran matadores traduce, implícitamente, una situación en que sólo las mujeres eran devoradas por los dioses" ${ }^{12}$. O mejor, sugiere que la posición de "comida de los dioses" (Maï demïdo, epíteto que describe la condición humana) es femenina - que la condición de viviente humano es femenina, por lo tanto. El muerto 'típico' es de este modo una mujer, así como el inmortal ideal es un guerrero. Ideal, pero paradójico: un matador muerto, un hombre que sólo realiza plenamente su potencia en esta doble relación con la muerte. Un matador murió al matar a su enemigo, se identifica con él, y sólo aprovecha efectivamente de estas muertes cuando muere: confrontado con los dioses, no es

12 Las almas de los niños tampoco son devoradas por los $M a i$. Su 'cuerpo' es refregado con el jugo de una fruta que les regenera la piel (el baño de inmortalidad en que son sumergidos los despojos de los muertos adultos es también llamado "baño del cambio de piel") y esto los transforma mágicamente en jóvenes adultos. 
tratado como un enemigo, porque es un enemigo, y por lo tanto es inmediatamente un Maï.

En el tiempo en que convirí con los Araweté, la posición de matador era menos importante y conspicua que la de peye, chamán. El lugar del cantante de las fiestas de caum era vicariamente ocupado por cualquier adulto capaz de acordarse de los cantos. En cambio, el ejercicio cotidiano del chamanismo cabía a los hombres que disponían del poder intransferible de manifestar la voz de los dioses.

Esta importancia diferencial de dos modos de ser masculinos puede ser atribuida, en parte, a la paz vivida entonces por los Araweté, pero creo que tiene un fundamento estructural. Un chamán es un muerto anticipado; en sus descripciones de sus viajes al cielo, siempre menciona que los dioses se refieren a él como "futura presa". Pero desempeña una función vital y social: es un ser-para-el-grupo. El matador, aunque es un dios anticipado, manifiesta una función mortal e individual: él es un ser-para-sí. El peye es el viviente por excelencia, el representante de los vivos en el cielo, y el canal de transmisión de los muertos celestiales. Es un mediador; ubicuo pero siempre distinto de lo que comunica, comunica lo que está separado. Su eficacia depende de estar vivo y traer a los muertos. En cambio, el matador no representa a nadie, pero encarna al enemigo, con quien se confunde; él es el lugar de una metamorfosis compleja, que sólo beneficia a sí mismo. Es cierto que el ideal de una sociedad compuesta integralmente de matadores está presente en la cultura araweté, y debe de haber sido doblemente 'vital' en su historia de tantas guerras. Pero, desde el punto de vista de la escatología personal, un moropïnà es alguien que ya pasó para el otro lado, convertido en enemigo y convertido en divinidad. Por eso, aunque el chamán esté para lo muerto como el matador para la divinidad, el primero está para los vivos como el segundo para los muertos. La sociedad sería imposible sin el peye; pero la masculinidad sería impensable sin la figura del moropïnà.

Los Maï son al mismo tiempo chamanes y matadores, vida y muerte. Son el arquetipo del chamán, puesto que detienen la ciencia de la resurrec- 
ción; y son el arquetipo del matador, puesto que son fusiones ambivalentes de ego y enemigo, bide y awin, que transforman a los muertos en ellos mismos a través de la devoración, exactamente como el homicida transforma al enemigo transformándose en él.

\section{EL PUNTO DE VISTA DEL ENEMIGO}

Exceptuando a la naturaleza relativamente elaborada del juego ventrílocuo de las canciones de enemigo, los materiales araweté sobre las relaciones entre el matador y su víctima sorprenden por su simplicidad, comparados a lo que se sabe sobre las resonancias simbólicas e imaginarias de la violencia guerrera en otras sociedades de la América tropical. Aparte de las limitaciones reales del etnógrafo, se puede atribuir esta esquemática apariencia al estilo general de esta sociedad que, poco acostumbrada a las grandes elaboraciones rituales, ha sido antes que nada víctima más que agresora ante las diversas sociedades enemigas con las que se ha enfrentado en las últimas décadas. La valorización de la condición de matador entre los Araweté no significa que ellos sean particularmente belicosos, ni particularmente eficaces como guerreros.

Es posible también, que la predación ontológica del exterior como condición de la reproducción social, tema característico de muchas sociedades amazónicas ${ }^{13}$, desempeñe un papel menos importante entre los Araweté que entre, digamos, los Tupinambá, los Jíbaro o los Munduruku. Esto tal vez se explique por un movimiento de traslado que se puede observar en la cosmología araweté: los contenidos simbólicos que, en otras sociedades amazónicas son transmitidos por el complejo guerrero, se encuentran en el caso araweté en gran parte dislocados hacia la relación entre los dioses y los hombres; el espacio y las funciones de exterioridad fueron apropiados por los Maï. Una comparación con los Tupi del siglo XVI refuerza esta inter-

\footnotetext{
cf. Viveiros de Castro 2002b.
} 
pretación (Viveiros de Castro 1992). La sociología caníbal de los Tupinambá, que sustentaba un sofisticado sistema ritual de captura, cautiverio, ejecución y devoración de enemigos-cuñados, se transforma entre los Araweté en una teología y una escatología que, aunque siempre marcadas por el lenguaje de la afinidad y el canibalismo, muestran un rendimiento ins tucional inferior a su riqueza ideológica.

Dicho esto, tal vez sea este despojo mismo lo que nos permita abordar directamente ciertos elementos esenciales del dúo matador-víctima en la Amazonía indígena.

Los materiales araweté manifiestan la presencia de un complejo simbólico muy general en la Amazonía - y ciertamente también encontrado afuera - que tiene como elementos mínimos los rasgos siguientes:

1. El estado de peligro místico en que cae el matador bordeado de, precauciones que apuntan a impedir fenómenos letales de 'rebote' causados directamente o indirectamente por la víctima;

2. Un comercio espiritual entre el matador y el enemigo muerto, y, al mismo tiempo, un paralelismo entre los procesos que ocurren en el cuerpo del matador y los que incurren en el de la víctima;

3. Un conjunto de ritos de homicidio concebidos como metabolización de la sangre del enemigo, con énfasis sea anabólica (digestión, sublimación en otras substancias corporales), sea catabólica (vómito, desangramiento);

4. Una prohibición de contacto entre el matador y los despojos del enemigo, los cuales atraviesan varios procesos de socialización, es decir, de apropiación por la comunidad del matador; en particular, aquellas culturas en las que se practica el canibalismo efectivo, el matador nunca puede comer de su víctima;

5. La abstinencia sexual del matador durante la reclusión, usualmente asociada a otras restricciones alimenticias y de conducta que evocan en algunos casos la práctica de la covada, y en otros una analogía explícita con el resguardo menstrual; 
6. El incremento del capital ontológico del matador al terminar el resguardo, expresado en una relación de anexación de ciertos atributos metonímicos de la víctima: alma, nombres, cantos, trofeos.

Voy a comentar solamente algunos aspectos de este complejo. En primer lugar, todo sucede como si el aumento de la potencia espiritual del matador dependiese de un período previo, durante el cual, el matador está sujeto a las influencias corporales de la víctima, o a sus poderes espirituales en tanto que estos son inherentes a ciertas sustancias vitales, especialmente a la sangre. Los procesos de elaboración de la sangre enemiga deben de ser, por lo tanto, abordados desde una doble perspectiva: si bien manifiestan una transformación del enemigo realizada en el matador, no dejan de ser, por otro lado, una transformación del matador llevada a cabo por la víctima. La idea de que el moropïnà muere después de su hazaña sugiere una alienación del matador, su captura por la imagen de la víctima ${ }^{14}$. Recuerdo que las reclusiones de homicidio, particularmente cuando funcionan como ritos de pasaje permitiendo el acceso a estatus valorizados (adulto en condición de casarse, líder espiritual, jefe de guerra), hacen un abundante uso de los símbolos clásicos de muerte y resurrección: liminaridad, silencio, desnudez, pérdida del nombre. En este sentido, la muerte de la víctima es efectivamente la muerte del matador, y el renacimiento del matador no deja de ser un renacimiento de la víctima.

En segundo lugar, las reglas que impiden un comercio excesivo entre el matador y su presa humana son particularmente sobresalientes en las sociedades que practican el canibalismo efectivo; en cambio, en aquellas en donde la decantación de la víctima en trofeos incomestibles (cabezas reducidas, dientes, escalpes) desempeñaba un mayor papel, no parece haber exis-

Compárese, por ejemplo., la podredumbre del matador araweté y su digestión de la sangre enemiga al canibalismo del matador yanomami, que remita la grasa y los cabellos de la victima, señal de que le comió el alma, $y$ a su posesión por el principio vital de ésta, que lo atormenta y enloquece de un modo análogo a la obsesión del matador araweté por el espiritu enemigo (Lizot 1976:13; Albert 1985:360-ss) 
tido prohibiciones de manipulación de estas partes por el matador ${ }^{15}$. La prohibición de que el matador toque el cadáver de su víctima evoca inmediatamente a la difundida regla amazónica que impide a un cazador comer su propia presa. Esta regla es usualmente interpretada en términos de una obligación de reciprocidad, que excluye el 'autoconsumo' como análogo al incesto etc. No hay duda que algo del mismo tipo se aplica a las presas humanas; por lo demás, en las sociedades adeptas a la caza de cabezas, tales trofeos debían ser igualmente socializados, es decir, debían beneficiar a toda la comunidad del matador, trayéndoles abundancia, fecundidad, protección contra los enemigos y prestigio. Lo que merece atención aquí, sin embargo, es menos la semejanza entre los tratamientos de las presas humanas y animales, por estar sujetas a una misma lógica del don, que las condiciones de posibilidad de tal aproximación.

La evidente continuidad, tanto técnica como simbólica, entre caza y guerra en la Amazonía fue, durante mucho tiempo, reprimida por los antropólogos. Tal vez porque reconocerla implicaría imputar a las culturas de la región una 'animalización' de los enemigos, o hasta podría terminar en explicar la guerra indígena en términos etológicos más que etnológicos. Pero estas consecuencias, inaceptables, no son inevitables si adoptamos un punto de vista menos extraño a las concepciones indígenas. La animalización del enemigo latente en el complejo bélico-venatorio depende de una primera, y aun más fundamental, humanización del animal. Para decirlo rápidamente: en la Amazonía indígena, las relaciones entre humanos y no-humanos, 'sociedad' $y$ 'naturaleza', no son concebidas como relaciones naturales, sino como relaciones propiamente sociales ${ }^{16}$. Guerra y caza son, literalmente, un mismo combate: un combate entre seres sociales, es decir, entre 'sujetos'. En este sentido, no hay discontinuidad entre la predación cinegética y la predación bélica; la alienación ritual del matador no es esencialmente diferente de la peligrosa identificación entre el cazador y su presa,

\footnotetext{
15 Vilaça (1992:101-15) sobre los Wari'. Para el segundo caso, Tayllor (1993) sobre los Jibaro, Menget (1993a) sobre los Munduruku y. Sterpin (1993) sobre los Nivacle.

Para esta idea, of. Viveiros de Castro 1992b, y sobre todo Descola 1993.
} 
que impone una separación en el orden del consumo, es decir, en el momento de la objetivación de la presa, que es prohibida al cazador. El carácter integralmente subjetivo de la relación ente predador y presa, humana o animal, es en mi opinión una crucial dimensión del fenómeno, la cual responde a la reversibilidad latente en esta relación: la recíproca presuposición, o determinación, entre matador y víctima.

Finalmente, las precauciones rituales del matador, en la medida en que son justificadas por una concepción de la sangre como inductor o signo de un cambio de estatus metafísico, traen a la escena a las mujeres. Ya se ha escrito bastante sobre el papel esencial de la comunidad femenina en los rituales guerreros y en el canibalismo; las observaciones de Lévi-Strauss (1984) a este respecto han sido ampliamente verificadas para la Amazonía. Por otro lado, la equivalencia simbólica o el encadenamiento causal entre condiciones masculinas asociadas a la imposición de la muerte y las condiciones femeninas involucradas en la producción de vida (homicidio y menstruación, reclusión ritual y gestación, guerra y casamiento etc.) es un tema que se encuentra un poco en todas partes, de la Amazonía a Polinesia, de Nueva Guinea a la Grecia antigua. Cabe mencionar que, por lo menos en algunos casos amazónicos, estas analogías sugieren un potencial de feminización del matador, su 'fecundación' o 'posesión' por la víctima, condición que debe ser ritualmente transmutada en un poder propiamente masculino de creación. Estas analogías sugieren también una serie de conexiones entre la transformación ritual de enemigos en víctimas; es decir, en identidades capturadas del exterior, y la generación de hijos, es decir, la producción de nuevas identidades en el interior del grupo. Eso nos lleva al segundo punto general.

\section{INTERIORIZACIÓN Y EXTERIORIZACIÓN}

Hemos visto que en el caso araweté opera una progresión. Una situación inicial caracterizada por una distancia social máxima y una distancia física mínima - la muerte violenta de un enemigo - desencadena una 'catástrofe fusional' que produce una identificación inestable entre los polos, y su 
resolución posterior en la forma de un englobamiento metonímico de la víctima por el matador. Este proceso puede ser encontrado, bajo múltiples variantes, en otras sociedades amazónicas. Entre los Araweté, la víctima se vuelve un apéndice espiritual del moropïnán, funcionando como su escudo o emblema en el ambiente caníbal del cielo. En otras culturas - los Nivacle son un buen ejemplo (ver Sterpin 1993:49-50) - la víctima es concebida como un traidor de los suyos, un elemento extranjero que se cambió de bando al grupo del homicida, manteniéndolo informado sobre los morimientos de su propio grupo. La víctima funciona aquí como una especie de mascota, es decir, como una subjetividad exterior salvaje que fue domesticada y desviada de su naturaleza original.

Los cráneos-trofeos de los Shipaya tenían la misma función de 'auto'delatores (Nimuendaju 1981:23-24), así como los espíritus de los Kayapó muertos por los Tapirapé, que se volvían familiares de los chamanes, arisándoles de los ataques de los Kayapó vivos (Wagley 1977: 184-85). Entre los Araweté, esta inversión del comportamiento de la víctima se verifica en el caso del jaguar. El espíritu de un jaguar muerto se queda junto a su matador, y se vuelve una especie de perro de caza: duerme debajo de su hamaca, mostrándole en sueños los sitios de caza abundante. El canto tradicional que conmemora la muerte de un jaguar obedece a la misma reverberación de los cantares de enemigo; el nombre de este canto es "futura víctima del jaguar", y pone en escena a un jaguar hablando de los humanos a quienes comerá. Una doble inversión, lógica y temporal, de punto de rista.

En otros casos, la humanidad de la víctima es radicalmente reciclada en nuevos componentes del grupo. El matador wari metaboliza la sangre del enemigo en semen, viniendo a generar un hijo que encarna el espíritu de la víctima, lo que completa la transmutación de la exterioridad caníbal y predatoria en consubstancialidad, cuidado paterno y comensalidad (Vilaça 1992:101-15). Los ritos jíbaro de celebración de la cabeza reducida culminan en la transformación de ésta en un hijo genérico (más precisamente, un feto) de las mujeres del grupo (Taylor 1993). Las cabezas-trofeo munduruku, 
igualmente, eran concebidas como hijos de una 'madre' masculina, el matador. Los Munduruku también ilustran otro tema común en la región: la cabeza del enemigo muerto era preparada y decorada para convertirse en la imagen étnica de un munduruku (Menget 1993a); esto evoca a los Tupi del siglo XVI, para los cuales un cautivo de guerra era laboriosamente depilado, pintado y adornado a imagen de sus futuros ejecutores.

Tenemos así un proceso general de asimilación de la víctima a la persona del matador o, más generalmente, a su grupo. Tal asimilación parece depender, en ciertos casos, del reconocimiento previo de la víctima como, de algún modo, semejante a sus agresores, y de este modo, solamente los extranjeros "a buena distancia" son considerados como presas legítimas - es lo que sucede entre los Jíbaro, que sólo tomaban cabezas de otros subgrupos de la misma etnia (Taylor 1985). Pero esta asimilación también puede producir esta semejanza a posteriori, como en los casos tupinambá y munduruku, en que el enemigo era 'nacionalizado' antes de ser ritualmente elaborado. Esta combinación de una diferencia y de una semejanza igualmente necesarias se cristaliza frecuentemente en la identificación de los enemigos a los afines: los cuñados-enemigos tupinambá (H. Clastres 1972) no son sino el ejemplo más célebre de una configuración amerindia muy general, en que la tensión característica de la afinidad - relación que tiene la semejanza como base y la diferencia como principio - es utilizada para pensar la categoría del enemigo y recíprocamente, es decir, donde los valores de la exterioridad predatoria forman el subtexto de la alianza matrimonial.

Todas estas ideas, vale la pena observar, presuponen la humanidad integral del enemigo. Esto significa que la relación entre matador y víctima solamente puede acarrear estas identificaciones místicas y fusiones rituales si es que dicha relación es inmediatamente entendida como una relación social. Por otro lado, sin embargo, la definición o producción ritual del enemigo como sujeto, o proceso de subjetivación del otro necesario a su asimilación por el mismo, contiene en sí, yo diría hasta como su condición, el momento inverso: la objetivación del matador, su alteración por la vícti- 
ma - su identificación al enemigo como enemigo. Vimos esto en la reverberación de los cantos de guerra araweté, en los cuales el matador se entiende como sujeto a partir del momento en que se ve a sí mismo por los ojos de su víctima, o mejor, en los cuales dice su propia singularidad por la boca de esta última. Podemos verlo más allá; la poética de la alteridad de los Araweté encuentra eco en la estética de la exterioridad de los Wayana: al partir en una expedición de guerra, los hombres wayana deben escarificarse con patrones decorativos representando jaguares y ares de rapiña - figuras que encaran los impulsos predatorios característicos de los enemigos (Van Velthem 1995:254-55). Ya habíamos visto algo semejante en la decoración corporal de los Maï.

Todo parece militar, en suma, a favor de una "impresionante indistinción entre el agresor y la víctima, a favor de una especie de esencia de la guerra", como tan bien lo dice Menget (1993b:29) a propósito de los Ikpeng. La interiorización del Otro es inseparable de la exteriorización del Yo; el domesticarse del primero es consubstancial al 'ensalvajarse' del último.

Nos queda preguntar: ¿Qué exactamente es asimilado cuando se asimila al enemigo? Los etnógrafos de la Amazonía mencionan recursos simbólicos muy variados que, de hecho, están lejos de ser mutuamente exclusivos en cada configuración cultural: nombres, cantos, substancias espirituales, energías vitales, identidades, rostros, principios de individuación, y así en adelante. Sin poder retomar aquí una argumentación ya desarrollada a propósito del canibalismo tupinambá (Viveiros de Castro $1992^{2}$ ), me limito a repetir aquí sus conclusiones, las cuales siguen de cerca la lección de los cantares de enemigo araweté.

Además de las substancias o principios más o menos reificados que cada sociedad (o cada etnógrafo) escoge como substrato y objeto de los procesos de asimilación del enemigo, pienso que lo que está en juego es, en último análisis, la incorporación de algo eminentemente incorporal: la posición misma de enemigo. Lo que se asimila de la víctima son los signos de su alteridad, $y$ a lo que se apunta es a esta alteridad como punto de vista o 
perspectiva sobre el Yo - una relación. Pero si lo que se devora, real o imaginariamente, de la persona del enemigo es su relación con el grupo agresor, esto significa también que el socius se constituye precisamente en la interfaz con su exterior, o, en otras palabras, que se sitúa como esencialmente determinado por la exterioridad. Al escoger como principio de movimiento a la incorporación de predicados provenientes del enemigo, la sociabilidad amerindia no puede terminar sino definiéndose por estos mismos predicados. ¿Cómo no llegar a esta conclusión cuando se ve que el protagonista de los momentos ritualmente más elaborados, e ideológicamente más densos, de estas sociedades es la unidad bifrontal del matador y su víctima, que se reflejan y reverberan al infinito?

\section{EL PUNTO DE FUSIÓN}

Si bien es verdad que "el punto de vista crea el objeto", no es menos cierto que el punto de vista crea el sujeto, puesto que la función de sujeto se define precisamente por la facultad de ocupar un punto de vista. En este sentido, la asimilación predatoria de propiedades de víctima, en el caso amazónico, debe de ser comprendida no tanto en términos de una física de substancias como en términos de una geometría de las relaciones, es decir, en tanto que movimiento de toma de perspectiva, en la cual las transformaciones resultantes de la agresión guerrera inciden sobre posiciones determinadas como puntos de vista.

Al proponer que la dinámica identitaria del par matador-víctima es un proceso de ocupación del punto de vista enemigo, estoy buscando discernir la peculiaridad de las ideas amerindias sobre la 'guerra'. Lejos de implicar un tratamiento del enemigo como una cosa (sistema material, cuerpo anónimo, autómata animal), el devenir del par matador-víctima involucra una confrontación de sujetos - no, ciertamente, al modo hegeliano de un combate de consciencias, hasta porque en esta dialéctica sólo hay maestros -, que intercambian puntos de vista y que alternan momentos de subjetivación y objetivación. Objetivación del matador por la subjetividad de la víctima, 
cuando ésta lo posee, controla y 'mata'; subjetivación del matador por la objetividad de la víctima, cuando esta se decanta en cantos, nombres, trofeos y otras sinédoques que señalan la nueva condición ontológica del matador.

De esta manera, se puede decir de la violencia guerrera amazónica lo que Simon Harrison dice de su análogo melanesio:

La agresión es concebida integralmente como un acto comunicativo dirigido contra la subjetividad de otro: y guerrear requería la reducción del enemigo no al estatus de una no-persona o de una cosa, sino, muy al contrario, a un estado de extrema subjetividad (1993:121).

Lo que lo lleva a concluir que la enemistad, en este tipo de sociedad, "es conceptualizada no como una mera ausencia objetiva de relaciones sociales, sino como una relación social tan definida como cualquier otra" (id. ibid.: 128$)^{17}$. El autor prosigue:

Asi como un don corporifica la identidad de su donador, también en la guerra de las tierras bajas de Nueva Guinea, el matador adquiere, mediante el bomicidio, un aspecto de la identidad de su victima. El bomicidio es representado sea como creando, sea como expresando una relación social, sea, también, como produciendo el colapso de una relación social, al fundir dos alteridades sociales en un solo ser (id.ibid.:130).

La relación entre el matador y su víctima, quintaesencia de la "lucha de los hombres", pertenece indudablemente al "mundo del don" (Lefort 1978). Pero, como se desprende del texto, esta relación ocupa una posiciónlímite en este mundo. Si bien la síntesis a priori del don une sujetos que permanecen objetivamente separados, la imposición de la muerte violenta y

Observación que recuerda inmediatamente el pasaje de Lévi-Strauss sobre la imposibilidad, "pour les indigènes", de concebir una ausencia de relación (1967:552-53) 
su lógica caníbal producen, al contrario, una síntesis donde toda distancia se anula. La relación es criada precisamente por la supresión de uno de sus términos, que es introjectado por el otro; la dependencia recíproca que une y constituye los sujetos del intercambio llega aquí a su punto de fusión -la fusión de los puntos de vista-, donde la distancia extensiva y extrínseca entre las partes se convierte en diferencia intensiva, inmanente a una singularidad dividida. La relación de predación se constituye a modo de subjetivación.

Erocando a un célebre concepto batesoniano, podríamos llamar a este proceso de anticismogénesis, puesto que parece menos jugar con una diferenciación de las perspectivas de los protagonistas de la "tragedia caníbal" (Combès 1992) que con un movimiento de aproximación fusional y de inmanentización de la diferencia ${ }^{18}$. En lugar de aparecer como término de una estructura que se desdobla o explica en polos opuestos, ego y enemigo, esta entidad 'monopolar' que es el matador se constituye por involución o implicación, determinándose como foco virtual de una condensación predicativa a donde la doble negación - yo soy enemigo de mi enemigo no restituye una identidad que ya estaría ahí como principio y finalidad, sino, al contrario, reafirma la diferencia y la hace inmanente - yo tengo un enemigo, y por eso lo soy. O el Yo lo es.

La agresión guerrera amerindia se revela entonces como un proceso de "transformación ritual del Yo", para pedir prestada a Simon Harrison su profunda definición de la guerra melanesia. Ésta nos conduce al otro lado del pensamiento salvaje, a la cara oculta de la luna estructuralista: antes que al totemismo, al simbolismo o a la metáfora, esta definición remite al sacrificio, al animismo y a la metonimia. Si la razón totémica (si toda razón no lo es) opera a través de la articulación reversible entre series que permanecen distintas de las relaciones que las unen, las figuras

La idea de un proceso anticismogenético me fue inspirada por la relectura del naven iatmul llevada a cabo en el notable estudio de Houseman \& Severi (1994) 
sacrificiales, tal como la del devenir matador-víctima, apuntan al contrario a la transformación de una serie en otra, operación "absoluta o extrema" (Lévi-Strauss 1962: 298) que se mueve en el elemento sombrío de la continuidad, de la indiscernabilidad y de la irreversibilidad. El matador y su víctima parecen estar, en suma, antes $d u$ côté de chez Léry-Brubl que $d u$ côté de chez Lévi-Strauss ${ }^{19}$. No se debe olvidar, sin embargo, que exactamente como Méséglise y Guermantes, hay más de un camino uniendo estos dos destinos. Realmente porque, como lo demostró su fusión final, ellos nunca estuvieron tan distantes el uno del otro como imaginaba el punto de vista - inevitablemente subjetivo - del Narrador.

\section{BIBLIOGRAFÍA}

\section{ALBERT, Bruce}

1985 Temps du Sang, Temps des Cendres: Représentation de la Maladie, Système Rituel et Espace Politique chez les Yanomami du Sud-est (Amazonie Brésielienne). Tesis de doctorado. Nanterre: Université de Paris X.

CLASTRES, Hélène

1972 "Les beaux-frères ennemis: à propos du cannibalisme tupinamba". En: Nouvelle Revue de Psychanalyse, 6 (Destins du cannibalisme), pp. 71-82.

CLASTRES, Hélène \& LIZOT, Jacques

1974 "La part du feu: rites et discours de la mort chez les Yanomami". En: Libre, 3, pp.135-149.

COMBES, Isabelle

1992 La Tragédie Cannibale chez les Anciens Tupi-Guarani. Paris: PUF

19 Del lado de más que del lado de 
DESCOLA, Philippe

1993 'Les affinités sélectives: alliance, guerre et prédation dans l'ensemble jivaro". En:

Descola P. \& Taylor A-C (eds.). La remontée de l'Amazone: anthropologie et histoire des sociétés amazoniennes. L'Homme, 126128, pp. 171-90.

DETIENNE, Marcel

1977 Dyonisos Mis à Mort. Paris: Seuil

HARRISON, Simon

1993 The Mask of War: Violence, Ritual and the Self in Melanesia. Manchester: Manchester University Press.

HOUSEMAN, Michael \& SEVERI, Carlo

1994 Naven ou le Donner à Voir: Essai d'Interprétation de l'Action Rituelle. Paris: Maison des Sciences de l’Homme/CNRS.

LEFORT, Claude

1951 (1978) 'L 'échange et la lutte des hommes". En: Les Formes de l'Histoire: Essais d'Anthropologie Politique. Paris: Gallimard, pp. 15-29.

LEVI-STRAUSS, Claude

1962. La Pensée Sauvage. Paris: Plon.

1967 Les Structures Élémentaires de la Parenté (2da. Edición/1era edición 1949). Paris: Mouton.

1984 "Cannibalisme et travestissement rituel". En: Paroles Données, pp. 141149.

LIZOT, Jacques

1976 Le Cercle des Feux: Faits et Dits des Indiens Yanomami. Paris: Seuil. 
MENGET, Patrick

1993a "Notas sobre as cabeças mundurucu". En: Viveiros de Castro E. \& Carneiro da Cunha M. (orgs). Amazônia: Etnologia e História Indígena. São Paulo: NHII-USP/FAPESP, pp. 311-21.

1993b 'Le propre du nom: remarques sur l'onomastique txicao". En: Journal de la Société des Américanistes, 79, pp. 21-31.

NIMIUENDAJU, Curt

1922 (1981). "Fragmentos de religiāo e tradição dos indios Sbipaya". En: Religião \& Sociedade, 7 , pp. 3-47.

STERPIN, Adriana

1993 "La chasse aux scalps chez les Nivacle du Gran Chaco". En: Journal de la Société des Américanistes, 79, pp. 33-66.

TAYLOR, Anne-Christine

1985 "L'art de la réduction". En: Journal de la Société des Américanistes, 71, pp. 159-73.

1993 'Les bons ennemis et les mauvais parents: le traitement symbolique de l'alliance dans les rituels de chasse auz têtes des Shuar (Jivaro) de l'Equateur". En: Héritier F. \& Copet-Rougier E. (eds). La symbolique de l'alliance. Paris: Archives Contemporaines, pp. 73-105.

VAN VELTHEM, Lúcia

1995 O Belo é a Fera: a Estética da Produção e da Predação entre os Wayana. Tesis de doctorado. Universidad de São Paulo.

VILAÇA, Aparecida

1992 Comendo Como Gente: Formas do Canibalismo Wari. Rio de Janeiro: Editora da UFRJ. 
VIVEIROS DE CASTRO, Eduardo

1992a From the Enemy's Point of View: humanity and divinity in an Amazonian Society (trad. C. Howard). Chicago: University of Chicago Press.

$1992 \mathrm{~b}$ "Sociedades indígenas e natureza na Amazônia". Tempo e Presença, 14 (261), pp. 25-26.

2002a "Perspectivismo e multinaturalismo na América indígena". En: A Inconstância da Alma Selvagem e Outros Ensaios de Antropologia. São Paulo: Cosac \& Naify, pp.345-401

2002b "O problema da afinidade na Amazônia". En: A Inconstância da Alma Selvagem e Outros Ensaios de Antropologia. São Paulo: Cosac \& Naify, pp.87-181.

WAGLEY, Charles

1977 Welcome of Tears: the Tapirapé Indians of Central Brazil. New York: Oxford University Press. 